Wilfrid Laurier University

Scholars Commons @ Laurier

6-2002

\title{
First Nations Child and Family Services and Indigenous Knowledge as a Framework for Research, Policy and Practice
}

Marlyn Bennett

Wilfrid Laurier University

Cindy Blackstock

Wilfrid Laurier University

Follow this and additional works at: https://scholars.wlu.ca/pcfp

Part of the Family, Life Course, and Society Commons, and the Social Work Commons

\section{Recommended Citation}

Bennett, M., Blackstock, C. (June 2002). First Nations child and family services and indigenous knowledge as a framework for research, policy, and practise. Paper presented at the Positive Systems of Child Welfare Conference, Waterloo, ON.

This Positive Systems of Child and Family Welfare International Conference (2002) is brought to you for free and open access by the Reports and Papers at Scholars Commons @ Laurier. It has been accepted for inclusion in Partnerships for Children and Families Project by an authorized administrator of Scholars Commons @ Laurier. For more information, please contact scholarscommons@wlu.ca. 


\section{Partnerships for Children and Families Project}

First Nations Child and Family Services and Indigenous Knowledge as a Framework for Research, Policy and Practice 


\title{
First Nations Child and Family Services and Indigenous Knowledge as a Framework for Research, Policy and Practice
}

\author{
Marlyn Bennett and Cindy Blackstock
}

Introduction

First Nations children were best cared for prior to colonization. Indigenous knowledge that was true since the beginning guided the values, beliefs and practices in caring for children, youth and families. Although the specific values, beliefs and practices varied in keeping with the significant diversity of Aboriginal ${ }^{1}$ peoples in Canada, care was generally provided according to a holistic worldview that viewed children as important and respected members of an interdependent community and ecosystem. The holistic worldview is the antithesis of the individual rights values upon which Canadian child welfare legislation and practice are premised.

First Nations child and family service agencies face the difficult task of building upon the cultural strengths of communal rights, interdependence and knowledge which are often diametrically opposed to the legal requirements to operate within the realm of euro-western provincial values, laws, regulations and standards pursuant to what is known as the delegated model of service delivery (Taylor-Henley and Hudson, 1992). The requirement to use provincial legislation arises from Section 88 of the Indian Act which provides for provincial laws of general application to apply on Indian reserves whenever the Indian Act is silent on an issue, such as in the case of child welfare. In order for First Nations child and family service agencies to deliver child welfare services on reserve, First Nations must reach an agreement with the provincial/territorial government to receive delegated authority pursuant to the provincial/territorial child welfare statute as well as a complementary agreement with the federal government to fund such services. The complexities of delivering services 
under the delegated model are significant. For example, it requires the ability to develop and deliver child welfare based on Indigenous ways of knowing and being within the ambit of euro-western child welfare legal pedagogy that has largely failed to meet the needs of Aboriginal children (Aboriginal Justice Inquiry, 2001). In addition, service inequities arise as First Nation child welfare agencies are funded by a national funding formula known as Directive 20-1 that does not adjust for the differences in provincial/territorial child welfare legislation (Assembly of First Nations, 2000).

The delegated model is an interim measure designed to meet the immediate and pressing needs of First Nations children and families while political leaders work to have Aboriginal laws recognized. Bradford Morse (1984) describes the limitations of programs predicated on eurowestern values and beliefs such as the delegated child welfare model as:

"The decision making power concerning critical issues affecting the colonized lies in the hands of the colonizers; the dominator gives little weight to the values, lifestyle and laws of the dominated; the colonialists interact with indigenous peoples in a manner that reflects the lower status and power of the latter; the colonizers import their standards, cultural values, laws and systems and impose them on the colonized so as to eliminate the latter's traditional structures."

Despite these significant challenges, there are many fine examples of programs where First Nations have bridged this gap effectively such as the Yellowhead Tribal Services Custom Adoption Program (Alberta), the Caring for First Nations Children Society Aboriginal Social Worker Training Program (British Columbia) and the Aboriginal Justice Inquiry - Child Welfare Initiative (Manitoba). A fundamental key to success for each of these programs is that they are all designed and delivered within Indigenous knowledge frameworks that are reflective of their local cultures. These successes inspire ongoing First Nations' efforts to affirm and promote Indigenous systems of knowledge, law and practice resulting in ideologically cohesive systems of care. 
This paper focuses on the process of affirming Indigenous knowledge and research processes that support First Nations social work practice and ideologies while identifying the complementary and conflicting impacts of non-Aboriginal social work research and practice. To accomplish the latter, the paper includes a critical analysis of research as a tool for the legitimization of knowledge within a euro-western framework and its implications on the colonization and marginalization of Aboriginal knowledge. We argue that academic research is itself inherently a colonizing process and before there can meaningful progress in promoting and including Indigenous knowledge, the research process itself must be de-colonized. In decolonizing the research, we advocate for an expansion of means to bridge the gap that exists between the research and policy processes and the realities of practicing within an Aboriginal social work context.

As a final point, this paper highlights the development of a national First Nations organization, the First Nations Child and Family Caring Society of Canada (FNCFCS), which brings together Indigenous knowledge, people and resources to validate traditional knowledge in the contemporary lives of First Nations children, families and communities. The establishment of a First Nations Research organization signals the beginning of developing a sustainable framework to support culturally appropriate systems of caring for First Nations children, youth, and families, which implies that there have been positive systems of child caring that have endured and continue to exist for as long as Aboriginal people have occupied North America.

\section{A Contemporary View of Culturally Appropriate Social Work: Challenges and}

\section{Opportunities}

Despite a United Nations' opinion that Canada is the best place in the world regarding quality of life measures, the reality of the Native child is bleak. A Native child is likely to be born poor and stay poor; she is, of all Canadians, most likely to 
die in infancy, to have fetal alcohol syndrome, to be sexually abused, to die in an accident, to drop out of school, and to commit suicide in adolescence. Almost every morbid statistic associated with the lack of child health and well being shows a gross and disproportionate representation of Native children ... Overall ... Native Canadian children can be ranked with children of the third world in both their quality of life and life chances (Report on the Standing Committee on Health, 1995, p.9, quoted in Awasis Agency of Northern Manitoba, 1997, p.1).

For First Nations peoples, colonization is not just a legacy of the past, it manifests itself every day in the way that we live surrounded by euro-western legal, social, spiritual and economic frameworks that continue to marginalize and, encroach on, First Nations Peoples and Aboriginal knowledge, and beliefs. In a child welfare context, colonization means that currently there are approximately 22,500 First Nations children in the care of Canadian child welfare authorities. To put this figure in context, in 1940, there were approximately 8,000 First Nations children attending residential school meaning that there are more children in the core of the child welfare system today than were in State care at the time residential schools were in full operation (Indian Residential School Survivors Society, 2002). This shocking statistic is unfortunately just one of the significant socio-economic challenges facing First Nations children, families and communities. Other challenges include issues such as poverty, youth suicide, accidental death, substance abuse, disproportionate incarceration rates and low graduation rates from high school. Despite these significant challenges, there continues to be a lack of awareness in Canadian society in general, and in the profession of social work specifically, of the cultures and histories of First Nations Peoples as well as the impacts of colonial policies, such as residential school and the child welfare system, on the well being of First Nations children, youth, families and communities. This ignorance, sourced in the inadequate telling of our history in Canadian schools and media, and the misinformation and misperceptions it generates, endures today as many Canadians believe that colonization and racism are issues of the 
past (Bennett, 2002) and not a challenge for the present. This perception of colonization as a concern of the past study negates the vigilance necessary to ensure that colonial thinking and actions do not continue to influence social work practice, policy or research. It allows ill advised social work practice to continue unabated as reflected in this statement by a First Nations Child and Family Service Director in British Columbia,

"There needs to be political will on behalf of the province to truly evaluate their current practices within their commitment to stop colonial practices and ensure service availability to First Nations peoples. MCF [Ministry for Children and Families] in particular needs to critically analyze their own system and practice regarding First Nations peoples. Their current approach of demanding First Nations meet a myriad of standards for operations and practice whilst independent reviews consistently determine that MCF practice with Aboriginal children is extremely deficient is certainly open to skepticism and carves out a distressing reality for First Nations children and families. MCF must role model its voiced commitment to quality and culturally based service delivery" (MacDonald, 2000).

Correcting colonial practice takes more than good will and commitment, it takes ongoing and active critical analysis and engagement of a profession in order to ensure that social work research, policy and practice works in partnership with Aboriginal Peoples to affirm and promote their ways of caring for children, youth and community. The significant socio-economic challenges facing First Nations children and families can feel overwhelming, but must frame a call to action as opposed to numbing us into inaction. In effect:

"[W]e must be careful of the dangers of academic detachment in reviewing the significant statistics demonstrating the crisis facing First Nations children, families and communities because numbers ...turn the brute facts into mathematical abstractions which camouflage feeling" (Snider, 1996, p.38).

This detachment is too often reflected in academic research about First Nations Peoples. If we succumb to this detachment, we are robbed of the "emotional leap into the reality of personal 
experiences which alone can penetrate specific dimensions of a human tragedy" (Snider, 1996, p.38).

Active engagement and understanding requires the development of an Indigenous research infrastructure to ensure that Aboriginal Peoples are the beneficiaries and not simply the subjects of more research that portrays the realities we live as neutral abstractions. An emphasis must be placed on ensuring that Indigenous knowledge and practices are accepted as valid in their own right and respectfully included in our deliberations, dialogue and practice as social workers. It is unfortunate that, in the main, Indigenous knowledge continues to be the purview of anthropology rather than integrated into various academic and professional disciplines including social work. Redhorse, Martinez, Day, Day, Pouport, and Scharnberg (2000) in their publication entitled Family Preservation: Concepts in American Indian Communities described the practice implications arising from the marginalization of Indigenous child and family knowledge and practices ... tribal child welfare and family preservation service systems seek to develop models that integrate natural helping networks with mainstream practice, non-Indian county systems fail to recognize or keep pace with this development ....Most county service professionals continue to regard tribal programs as inferior or without merit and, in some cases, disregard cultural practice. Consequently there is a problem with planning and coordination of services (p.37).

The development of Aboriginal courses or programs within the social work discipline is an important beginning in establishing a respectful social work paradigm for working with Aboriginal Peoples. However, too often, Aboriginal social work is a specialized and elective area of study rather than being recognized as an integral part of social work education and practice alongside euro-western ideologies and theoretical frameworks. The development of Indigenous research capacity will inform social work, but this must be accompanied by significant and sustained efforts by 
social work professionals to value, understand and include Indigenous knowledge and ways of caring for children, families and communities in their education and practice.

\section{Innovation Based on Indigenous Knowledge and Tradition}

There are good examples of respectful inclusion of Indigenous knowledge in social work. For example, significant modifications in the Social Work Program at the University of Manitoba have been proposed largely in response to anticipated changes in the restructuring of the child welfare system in the Province of Manitoba through the Aboriginal Justice Inquiry - Child Welfare Initiative (AJI-CWI). The AJI-CWI proposes substantial changes to the way in which child and family services will be delivered to the First Nations, Metis Peoples and the general public in Manitoba. The most profound change to date in this initiative is the increased participation by the Aboriginal Peoples in the restructuring process as well as a willingness on the part of the Manitoba Government to share some aspects of its child welfare jurisdiction with Aboriginal peoples in Manitoba by:

- recognizing a province-wide First Nations right and authority over the delivery of child welfare services by extending and expanding the off-reserve jurisdiction to provide child welfare services to First Nations citizens;

- recognizing a province-wide Metis right and authority over the delivery of child welfare services to its constituents; and,

- intending to restructure the existing child welfare system through legislative and other changes (AJI-CWI, 2001).

This new relationship will see the responsibility for management of services delegated to two

First Nations (both on and off-reserve) child and family service authorities and one Metis child and family service authority. The responsibility for management of services to other children and families (non-Aboriginal) will be delegated to a General Child and Family Services Authority. The new Authorities to be set out under this new initiative are as follows: 
- a First Nations of Northern Manitoba Child and Family Services Authority;

- a First Nations of Southern Manitoba Child and Family Services Authority;

- a Metis Child and Family Services Authority; and,

- a General Child and Family Services Authority (for all other families) (AJI-CWI, 2001).

Under these proposed changes, the Province will continue to maintain ultimate responsibility

for the safety and protection of children in Manitoba. It will establish laws, policies and standards for the new system and will work together with the four Authorities in providing services. The four Authorities will have new and expanded rights and responsibilities granted by the Minister and these will be recognized in new legislation. Each Authority will design and manage the delivery of child and family services throughout the Province and assist in setting standards as well as have the authority to decide and provide funding to various agencies under its mandate who qualify to deliver services under the new system (AJI-CWI, 2001). The services delivered by the Aboriginal agencies will be culturally appropriate and based on an understanding of Aboriginal families and communities.

Under this system, all four Authorities (and their funded agencies) will work together to serve the needs of people across the Province. Referred to as concurrent jurisdiction, this means that all four Authorities (and the agencies operating through them) will have responsibility for services to the entire Province at the same time. This marks a major change from the current system in which only one child and family service agency has responsibility in any given location in the Province. The central objective of the new system is to ensure that people receive services through the most culturally appropriate Authority. All families and children becoming involved with child and family for the first time will be guided through a process that will connect them with the appropriate Authority. The streaming process is based on the belief that families will want to receive services through the Authority with which they most closely identify (AJI-CWI, 2001). 
Public feedback on the proposed child welfare system changes was jointly solicited by the Aboriginal and Provincial partners during a seven-week period, ending September 30, 2001. The objectives were to provide Manitoba citizens without formal representation on the AJI-CWI with an opportunity to comment on the proposed changes and to assist in identifying the strengths, limitations and/or gaps in the changes being proposed to the child and family services system. Public feedback reflected a strong and widespread support (AJI-CWI, 2002) for the overall vision for a restructured child and family services system described in the Promise of Hope: Commitment to Change document. Support was indicated for the overall goals, the governance model, the use of a streaming methodology combined with choice in determining service jurisdiction, the service objectives proposed, the emphasis on the development of a culturally appropriate workforce, and proposed changes to how the system would be funded (AJI-CWI, 2002).

Because of the complexity and the ongoing work of the AJI-CWI process, only some of the significant aspects of the proposed changes suggested have been described. There is no doubt a great deal of work remaining ahead for those involved in overseeing the change. Because of greater participation by Aboriginal people in this restructuring process, there will be an increased demand for more Aboriginal social workers familiar with an Aboriginal context. The University of Manitoba has begun developing curricula to address the need for an expanded Aboriginal labour force educated in the Indigenous ways of helping in child welfare.

Yellowhead Tribal Services Agency in Edmonton, Alberta has been widely recognized for the development of it's Custom Adoption Program based on the culture of First Nations communities. It is guided by a council of Elders and is responsive to Alberta's legal adoption requirements. The program takes a holistic community approach to adoption, viewing the child as a 
member of a caring community and but the sole responsibility of parents. It is an extension of the traditional practice of the community assuming care for a child when a parent or extended family members were unable to do so, as a natural part of community life and not a unique or unusual experience. The program involves the community in supporting and affirming the important roles of the biological and adoptive parents and extended families, eliminating much of the stigma and isolation resulting from mainstream adoption processes for First Nations.

The Caring for First Nations Children Society Aboriginal Social Worker Training Program provides comprehensive training for social workers employed by Aboriginal child and family service agencies. The development of the program was motivated by an acknowledgement that mainstream education programs for social workers did not adequately prepare them to work in an effective and respectful manner with Aboriginal children, families and communities. A committee of First Nations child and family service agency staff, as well as representatives from British Columbia's Ministry for Child and Family Development and the Department of Indian and Northern Affairs Canada, worked in partnership with the Caring for First Nations Children Society to develop this program.

The training is competency based, integrating three broad areas of understanding: (1) Knowing about First Nations cultures and contexts; (2) developing best practices within a First Nations child and family service context; and, (3) respecting the requirements of provincial legislation and practice standards. In order to enhance participant experience and appreciation of the diverse cultures of Aboriginal peoples in British Columbia, the training is provided, whenever possible, in Aboriginal communities and features a field training component which seeks to affirm and promote community specific knowledge. The program also includes a graduation ceremony hosted by an Aboriginal community. These graduation programs underscore the connection of social workers 
with the community in promoting the care of children and youth as well affirm the important role the social workers will play in community life.

Since the completion of the development of the program in 1999, over 250 First Nation participants have completed one or more of the four modules of the training program (Caring for First Nations Children Society, 2002.) Evaluation results strongly support this training approach as participants find the training relevant, and practical to apply in their work with Aboriginal communities. The Caring for First Nations Children Society has recently expanded its range of training programs to include community workshops, supervisory training and the development of training methods specific to Aboriginal child and family services.

These examples attest to the exemplary results that occur when programs and services are developed by Aboriginal Peoples informed by their traditions, knowledge and cultures. These examples also indicate the need for enhanced Indigenous research, policy and practice infrastructures to support the development of culturally appropriate Aboriginal child welfare initiatives across the country and internationally.

The advocacy efforts of First Nations child and family service agencies in Canada to enhance Indigenous research and policy capacity culminated in a national meeting of First Nations child and family service providers at the Squamish Nation in 1998. This meeting resulted in a consensus to develop a new national Indigenous organization, which became the First Nations Child and Family Caring Society of Canada (FNCFCS). The primary objective of the FNCFCS is to promote First Nations child and family services interests, knowledge and best practices of First Nations systems of care. The FNCFCS has, in partnership with the Center of Excellence for Child Welfare, established a First Nations research site in Winnipeg Manitoba that will promote Indigenous knowledge, conduct 
research, and assist in building research capacity in First Nation agencies (First Nations Child and Family Caring Society, 2002.) More importantly, the establishment of this research site signals the establishment of research paradigms, as well as legal and policy frameworks that complement, Aboriginal ways of caring for children. The next two sections of this paper discuss both the pitfalls of traditional research approaches and the benefits of Indigenous knowledge as a research framework to guide the FNCFCS in conducting research with First Nations child welfare agencies.

\section{Affirming and Promoting Indigenous Knowledge and Research}

The purpose of the FNCFCS's First Nations Research Site is primarily to conduct research engaging individuals working with First Nations child welfare agencies, to enhance research capacities respectful of First Nations values and ways of caring for children. We are cognizant, at the same time, that research using "traditional" academic methodologies is experienced as a colonizing process by many Aboriginal peoples. These research methodologies play a significant role in colonization, by being presented as the primary means for the legitimization of knowledge (Cajete, 2000; Smith, 1999).

Too often, a concept held as true for millennia by Indigenous Peoples perpetuated through their histories, is only accepted by non-Aboriginal social workers or scholars if validated by established research evidence. This perspective of colonialism highlights the conquest and control of nonwhite, non-European peoples and their ways of constructing knowledge. Yazzie (2000) notes that colonization is part of the theory of Social Darwinism:

... After Charles Darwin developed the theory of evolution, Herbert Spencer came up with the concept of "survival of the fittest"... He went on to argue that some people are "fitter" and thus "superior" to others. ... The theory of Social Darwinism assumes that a certain group of people has the right to make decisions for others and to control the government and the economy. ... Social Darwinism also assumes that 
there are "inferior people," and history and contemporary practice show that they are women, non-Christian, and people of colour. In Northern America, that includes Indians and other Indigenous peoples (p.42).

In order to understand how research can be a colonizing process, one only has to look to the subtle ways in which First Nation students are indoctrinated by Canadian universities (Cajete, 2000; Hampton, 1995). Those of us of Aboriginal descent are not from homogeneous cultures and backgrounds, yet in Western learning institutions, we are expected to fit into "one size fits all" institutions (Bailey, 2000). The unwritten rules of the dominant society require that we all speak English, write research papers and exams assed on specific criteria outside of our Indigenous worldviews, and learn what others decide we need to know. Nor does what we learn in these institutions assist us in reaffirming and legitimizing our own ways of knowing and doing (Cajete, 2000; Colorado, 1992; Hampton, 1995; Martin, 2001). Furthermore, the language in which knowledge is imparted is not ours by birth.

Battiste and Youngblood Henderson (1999) note that these sorts of activities establish the dominant group's knowledge, experience, culture and language as the universal norm. The educational experience of Aboriginal People exemplifies the continued colonization of Aboriginal peoples where the colonizers (dominant society in Canada) reinforce their culture by making the colonized (Aboriginal students) conform to their expectations (Battiste \& Youngblood Henderson, 1999). Once we leave these institutions, we are expected to reflect what we have learned in everything that we do, even in Aboriginal communities. Western learning institutions and their research agendas do not mirror who we are as First Nations. The structures, content, processes and staff within these institutions are controlled primarily by members of the dominant society who, 
consciously or unconsciously, reinforce the marginalization of Indigenous knowledge systems (Bailey,

2000; Battiste and Youngblood Henderson, 1999; Kirby \& McKenna, 1989).

The creation of knowledge is based on what Battiste and Youngblood Henderson (1999)

call eurocentricism. Eurocentricism supports the belief in the superiority of European peoples over

non-European (Indigenous) peoples extends to the lack of recognition (or the ignorance) of

Indigenous knowledge systems and ways of knowing and doing. Discussions the eurocentric need to define Indigenous knowledge, Battiste and Youngblood Henderson (1999) stated in their treatise on

Protecting Indigenous Knowledge and Heritage that:

Eurocentricism relies on arbitrary definitions that have no relationship with the life forces that Indigenous peoples use to understand life. Modern Eurocentric thinkers believe there are numberless ways in which they can classify ideas, objects, and events in ecology. The system of classification and the definitions used within it are based on the desires or purpose of those who created the system. The definitions are judged to be valid if they advance the desires or purposes of the people who fabricated them, allowing them to measure, predict, or control events. Since the validity of the system rests on its ability to contribute to particular ends, no basis exists for saying that one classification system portrays the "real" world more accurately than another does. Given the principles of diffusionism and universality, however, Eurocentric thinkers automatically assume the superiority of their worldview and attempt to impose it on others, extending their definitions to encompass the whole world. Typically, this quest for universal definitions ignores the diversity of the people of the earth and their views of themselves (p.36-37).

Aboriginal sources of knowledge and ways of knowing and doing are grounded in our languages, the land, animals, our Elders and spiritual messengers (Auger, 1997). They are reflective in our own systems of child care. Each of these elements of knowledge is more complex when the plurality of Indigenous knowledge systems is considered (Cajete 2000; O’Meara \& West, 1996). While Indigenous knowledge is marginalized, there is no paucity of research on Aboriginal peoples 
being conducted by university researchers around the world. In fact, globally, Aboriginal peoples feel that they are the most over researched group in the world (Smith, 1999).

Research has long been the domain of the "privileged". Research about Indigenous Peoples and their lands by "outsiders," "experts," and "authorities," who have too often dissected, labeled, and dehumanized Indigenous Peoples, acting as helpers in the colonial dispossession of Indigenous land and cultural heritage (Martin, 2001). Volumes of research on Aboriginal People in Canada have been generated, but there is relatively little research that Aboriginal Peoples have been able to define for themselves (Gilchrist, 1997). This is beginning to change as more and more Aboriginal People attend university and begin to challenge the traditions of Western research methods and ethics.

Our purpose is not to question the legitimacy of the current institutions of "higher" learning, as this has been done many times by other Indigenous scholars in Canada and elsewhere (Battiste \& Barman, 1995; Battiste \& Youngblood Henderson, 1999; Cajete, 2000; Hampton, 1995; Martin, 2001; Smith, 1999). Rather, our intent is to highlight the significant limitations of restricting concepts of learning and legitimate knowledge to the current realm of academic study. There are many benefits that First Nations Peoples have and will gain from formal education. We believe that academia will be enhanced by respecting, and supporting Indigenous systems of knowledge.

The success of our own partnerships with the Universities of Toronto and Manitoba in setting up the First Nations Research Site attests to these institution's willingness to explore reciprocity in knowledge development. However, in order to strengthen the capacity of Aboriginal people to conduct research in the child welfare field (as well as other fields), the Research Site is facing the 
daunting challenge of de-colonizing the research process to legitimize our own ways of generating Indigenous knowledge that is controlled, owned and protected by First Nations Peoples collectively.

We should not contribute further to the public silencing of Aboriginal voices as has been done so many times in the past (Kirby \& McKenna, 1989). Instead, we recognize that we have an ethical responsibility to support initiatives that create opportunities for First Nations People to conduct research congruent with Indigenous values and priorities. Our research should be empowering, leading to positive results for First Nations communities. Not only will the involvement of the community be instrumental in determining our research agenda and methodologies (Battiste \& Youngblood Henderson, 1999), community members will be given opportunities to benefit from training and employment opportunities that may be generated by the research. Local systems of knowledge will be respected, as each is unique.

Snider (1996), in quoting Wiesel, a writer and survivor of the Nazi concentration camps, remarks that "knowledge burdens us with heightened responsibilities" (p.45), especially when it comes to the representation of "truth". The First Nations research site will develop culturally appropriate ethical guidelines supporting Indigenous values to ensure that the knowledge gained is used to the legitimate advantage of communities. Issues such as the right to be included in research that is relevant and to be fully informed about the purpose, methods and use of the research (Gilchrist, 1997) will be central in the development of these ethical guidelines. In these guidelines, we affirm our own Aboriginal philosophies and worldviews (Fitznor, 1998) and move a step forward in de-colonizing the existing research traditions. We do this by reaffirming the coherent culturally appropriate ways of caring for children stemming from Aboriginal values. 


\section{The First Nations Research Site and the Partnership with the Centre of Excellence for Child Welfare}

The First Nations Research Site is the product of a partnership between the First Nations

Child and Family Society of Canada, the Centre of Excellence for Child Welfare (CECW), and the University of Manitoba. The Site resulted from discussions between the board members of the First Nations Child and Family Society and management of the CECW. The Dean of the Faculty of Social Work, on behalf of the University of Manitoba, agreed to house the First Nations Research Site and provide administrative and resource supports within the Faculty of Social Work. The First Nations Research Site is one of four research sites connected with the CECW. The organizational structure of this partnership is detailed in the diagram below: 


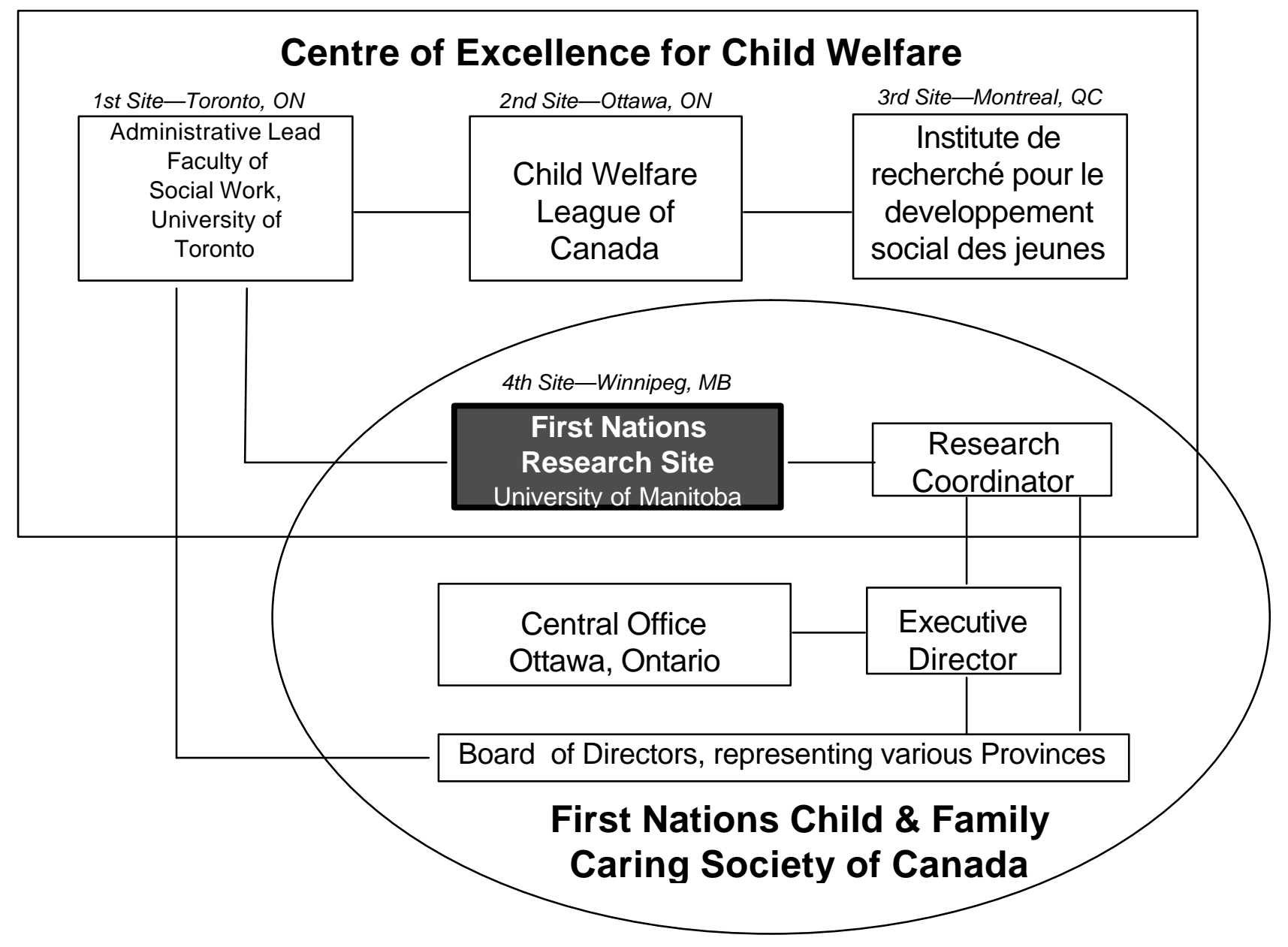

Planning started in April 2001, and the First Nations Research Site became fully operational in November of the same year. The site is managed by a full time Research Coordinator. The Research Coordinator draws upon the academic expertise within the University of Manitoba's Faculty of Social Work.

The FNCFCS provides the overall direction to the First Nations Research Site, reserved site staff work in partnership with the Society. The role of CECW in the First Nations Research Site is 
to assist the Site staff with training, and access to research and other resources. CECW provides direction in conducting analyses of the data from the Research Site's studies.

The First Nations Research Site is to provide a national research forum for First Nations child welfare agencies, researchers, policy makers, and others interested in the development of child welfare research which incorporates and respects Indigenous knowledge and the cultural worldviews of First Nations in Canada. The goals of the First Nations Research Site are:

- to assist the Centre of Excellence for Child Welfare in analyzing and reporting on Canadian child welfare data, specifically data within the First Nations child welfare context;

- to share innovations and issues in practice, policy, knowledge, research, skill development, and administration in First Nations child welfare;

- to stimulate discussion between local, regional, provincial and national child welfare agencies on current research, policies and/or practices that impact on or benefit First Nations children, youth, families and/ or communities;

. $\quad$ to promote networking and the exchange of ideas among First Nations practitioners, academic researchers, policy makers and advocates who work in the First Nations child and family services field;

- to assist in building and strengthening research capacity among First Nations individuals, agencies and organizations engaged in child welfare research, policy and/or practice;

- to build a pool of resources and network with academic and private First Nations researchers;

- to promote the training of professional staff, researchers, caregivers and volunteers; and

- to promote the development of techniques for evaluating the programs and services delivered to First Nations children, families and communities by the First Nations child welfare agencies and organizations in Canada.

The following two objectives have been established to assist the First Nations Research Site in

meeting some of its goals as outlined above by:

- developing and maintaining a data base which identifies the First Nations researchers (both academically and privately) and the types of child welfare research being conducted by First Nations or Indigenous agencies, researchers and/or non-government organizations in Canada, the United States and internationally; and 
- developing an online journal to assist in the collection and dissemination of information and research to all child welfare agencies, organizations and other non-government organizations that work with or interested in working with First Nations children, families and communities in Canada.

As a national organization that seeks to provide services to the approximately 120 First

Nation child welfare agencies in Canada, the First Nations Child and Family Caring Society of

Canada recognizes the importance of building partnerships where Indigenous knowledge is not only respected, but allowed to flourish. The First Nations Child and Family Caring Society's collaboration with other Aboriginal organizations, through research conducted by the First Nations Research Site will be an important step in supporting Aboriginal child welfare organizations. It will help to showcase the best Aboriginal child welfare practices for Canada and the world. Indeed, there are many innovative initiatives in Aboriginal communities, with the promise of making the fields of social work and child welfare more congruent with the needs of Aboriginal peoples.

\section{Conclusion}

The First Nations Research Site provides a foundation for affirming Indigenous knowledge as an essential component of redressing the impacts of colonization and supporting our children, youth and families to meet contemporary and future challenges. It embodies the importance of partnerships between First Nation organizations and other research centers to bridge gaps in meeting community needs and contemporary social work education.

We start from the premise that First Nations have their own knowledge systems which must survive for the benefit of future generations. We must begin the process of conducting our own research to contribute to Indigenous knowledge which will undoubtedly grow with future generations. We hope that our written words fuel discussions that will help shape individual, community and 
government action to de-colonize all systems, including those that touch upon the construction, validation and preservation of knowledge. We hope that this process ultimately leads to paths of respect, freedom and equal opportunity for First Nations Peoples in Canada. In First Nations communities, positive systems of child and family welfare prior to colonization were predicated on Indigenous values and ways of knowing, doing and being. The challenge for us is to ensure that these positive systems and the best practices they foster are brought to the forefront, shared and adequately expressed through our own Indigenous research frameworks. 


\section{References}

Aboriginal Justice Inquiry - Child Welfare Initiative. (2002). Summary Report on the AJI-

CWI Phase 3 Public Feedback Process. Manitoba:Winnipeg.

Aboriginal Justice Inquiry - Child Welfare Initiative. (2001). Promise of Hope:

Commitment to Change. Manitoba: Assembly of Manitoba Chiefs; Manitoba Metis Federation; Manitoba Keewatinowi Okimakanak; Government of Manitoba

Auger, D. (1997). Empowerment through First Nation Control of Education: A Sakaw

Cree Philosophy of Education. In First Nations in Canada: Perspectives on Opportunity,

Empowerment, and Self-Determination (pp.326-351). Toronto: McGraw-Hill Ryerson Limited.

Assembly of First Nations and the Department of Indian Affairs and Northern Development.

(2000). First Nations Child and Family Services Joint National Policy Review. Ottawa: Assembly

of First Nations.

Awasis Agency of Northern Manitoba. (1997). First Nations Family Justice: Mee-noo-

stah-tan Mi-ni-si-win. Thompson: Awasis Agency of Northern Manitoba.

Bailey, B. (2000). A White Paper on Aboriginal Education in Universities. Canadian

Ethnic Studies, 32(1), p.126-135.

Battiste, M. \& Barman, J. (1995). First Nations Education in Canada: The Circle Unfolds.

Vancouver, BC: UBC Press.

Battiste, M., \& Youngblood Henderson, M. (1999). Protecting Indigenous Knowledge

and Heritage: A Global Challenge. Saskatoon, SK: Purich Publishing Ltd. 
Bellefeuille, G., Garrioch, S., \& Ricks, F. Breaking the Rules: Transforming Governance in

Social Services. Thompson: Awasis Agency of Northern Manitoba.

Bennett, M. (2002). Aboriginal Youth and Racism: A Review of the Literature. Paper prepared for the Department of Canadian Heritage: Winnipeg, MB.

Caring for First Nations Children Society. (2002). Aboriginal Social Worker Training

Program Available on line at www.cfncs.com.

Cajete, G. (2000). Native Science: Natural Laws of Interdependence. Sante Fe, New Mexico: Clear Light Publishers.

Colorado, P. (1988). "Bridging Native and Western Science." Convergence, 21, p.49-72.

Chartrand, P., McKay, E., Whitecloud, W., \& Young, D. (2001). Aboriginal Justice

$\underline{\text { Inquiry Implementation Commission: Final Report. Available online at www.ajic.ca. }}$

Department of Indian Affairs and Northern Development. (2002). Basic Departmental

$\underline{\text { Data }-2001}$. First Nations and Northern Statistics Section, Corporate Information Management

Directorate, Information Management Branch. Ottawa: Canada.

First Nations Child and Family Caring Society of Canada. (2002). History and Background Available on line at www.fncfcs.com.

Fitznor, L. (1998). The Circle of Life: Affirming Aboriginal Philosophies in Everyday Living. In D.C. McCance (Ed.), Life Ethics in World Religions: University of Manitoba Studies in Religion (pp.21-40). Atlanta, Georgia: Scholars Press.

Gilchrist, L. (1997). Aboriginal Communities and Social Science Research: Voyeurism in Transition. Native Social Work Journal, 1(1), p.69-85. 
Hampton, E. (1995). Towards a Redefining of Indian Education. In M. Battiste and J. Barman (Eds.), First Nations Education in Canada: The Circle Unfolds (pp.5-46). Vancouver: University of British Columbia Press.

Indian Residential School Survivors Society Newsletter. (2002). The Survivor's Journey: The Newsletter of the Indian Residential School Survivor's Society. West Vancouver: Indian Residential School Survivor's Society.

Issac, T. (1999). Aboriginal Law: Cases, Materials and Commentary. Saskatoon: Purich Publishing.

Kirby, S., \& McKenna, K. (1989). Experience, Research, Social Change: Methods from the Margins. Toronto: Garamond Press.

Martin, K. (2001). Ways of Knowing, Ways of Being and Ways of Doing: Developing a Theoretical Framework and Methods for Indigenous Re-Search and Indigenist Research. Available online at www.aiatsis.gov.au/rsrch/conf2001.

MacDonald, K. (2000). First Nation Summit Action Committee for First Nations Children and Families Discussion Paper. North Vancouver: First Nations Summit.

Morse, B. (1984). Native Indian and Metis Children in Canada: Victims of the Child Welfare System. In Race Relations and Cultural Differences: Educational and Interpersonal Perspectives (pp.259-277). New York: St. Martin’s Press.

O’Meara, S., \& West, D.A. (Eds.). (1996). From Our Eyes: Learning from Indigenous Peoples. Toronto: Garamond Press.

RCAP. (1996). CD Rom: For Seven Generations: An Information Legacy of the Royal Commission on Aboriginal Peoples. Ottawa: Libraxus Inc. 
Redhorse, J., Martinez, C., Day, P., Day, D., Pouport, J., \& Scharnberg, D. (2000). Family

Preservation: Concepts in American Indian Communities. Seattle, Washington: Casey Family

Programs.

Smith, L.T. (1999). Decolonizing Methodologies: Research and Indigenous Peoples.

London \& New York: Zed Books Ltd. and University of Otago Press, Dunedin, Australia.

Snider, J. (1996). Scholarship, Morality and Apologies for Empire. In S. O’Meara and

D.A. West (Eds.), From Our Eyes: Learning from Indigenous Peoples. Toronto: Garamond Press.

Taylor-Henley, S., \& Hudson, P. (1992). Aboriginal Self-Government and Social Services:

First Nations - Provincial Relationships. Canadian Public Policy, 18 (1), p.13-26.

Yazzie, R. (2000). Indigenous Peoples and Postcolonial Colonialism. In M. Battiste (Ed.),

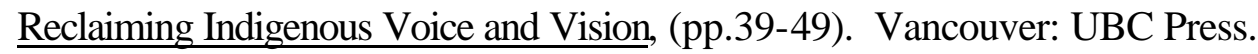

\footnotetext{
${ }^{1}$ Within Canada, Aboriginal peoples are compromised of various groups, who are recognized constitutionally as the Inuit, Métis and First Nations (or Indian) people. Readers will note that words such as "Aboriginal," "First Nations," "Native" and/or "Indigenous" have been capitalized throughout this paper. Many Aboriginal Peoples and Indigenous researchers in Canada and internationally have argued that such words should be capitalized when referring to a specific people, in much the same manner that words like "English" and "French" are capitalized (Issac, 1999). The authors of this report agree with this perspective and hence the capitalization of those words is found throughout this paper.
} 


\section{SOCIAL WORK}

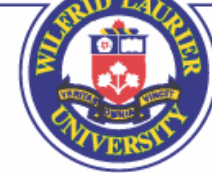

Partnerships for Children and Families Project

Wilfrid Laurier University

Waterloo, Ontario, Canada, N2L 3C5

Email: partnerships@wlu.ca

Local: (519) 884-0710 ext.3636

Toll Free: 1-866-239-1558

Fax: $\quad$ (519) 888-9732 